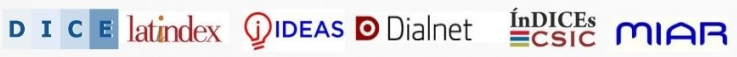
Econpapers ERIHPIUS Surcupira

\title{
A MULHER NO TURISMO RURAL: UM ESTUDO NO ROTEIRO CIRCUITO DO SOL DO MUNICÍPIO DE NOVA AURORA- PR
}

\author{
Cinara Kottwitz Manzano Brenzan \\ https://orcid.org/0000-0002-1684-2320 \\ Mestre em Administração (UEL) \\ Docente no Curso de Administração (UNIOESTE) \\ cinaramanzano@yahoo.com.br. \\ Kátia Janaína Frichs Cotica
}

https://orcid.org/0000-0003-0510-3909

Mestranda em Desenvolvimento Rural Sustentável (UNIOESTE)

E-mail:jcotica@uol.com.br.

Marcus Henrique Rolim Leite

https://orcid.org/0000-0001-8716-518

Graduado em Hotelaria (UNIOESTE)

E-mail: marcusleite.rolim@hotmail.com

Rosislene de Fátima Fontana

https://orcid.org/0000-0003-2504-1928

Doutora em Turismo e Hotelaria (UNIVALI)

Docente do curso de Hotelaria (UNIOESTE)

Email:rosislene.fontana@unioeste.br/rosislene.fontana@gmail.com.

Para citar este artículo puede utilizar el siguiente formato:

Cinara Kottwitz Manzano Brenzan, Kátia Janaína Frichs Cotica, Marcus Henrique Rolim Leite y Rosislene de Fátima Fontana (2021): "A mulher no turismo rural: um estudo no Roteiro Circuito do Sol do município de Nova Aurora- PR", Revista Turydes: Turismo y Desarrollo, n. 30 (junio / junho 2021). En línea:

https://www.eumed.net/es/revistas/turydes/vol-14-no-30-junio-junho-2021/mulher-turismo-rural

\section{RESUMO}

Este artigo objetiva proporcionar uma análise sobre experiências de mulheres nas agroindústrias e seu empoderamento a partir da organização do Roteiro Circuito do Sol no Município de Nova Aurora, com a abordagem do Turismo Rural e Empoderamento Feminino. Os dados foram coletados por meio de pesquisa qualitativa, bibliográfica e documental, entrevistas semiestruturada e visitas nas agroindústrias pertencentes ao Circuito do Sol, na Prefeitura e na Emater. Após a realização das entrevistas e visitas nas agroindústrias, pode-se afirmar que a presença do empoderamento das mulheres organizadas no turismo rural do município de Nova Aurora é visível. Constata-se, com base nos relatos das mulheres entrevistadas, um sentimento de medo no início da atividade, porém de 
valorização, orgulho e aumento da autoestima pela posição conquistada com o tempo. Os resultados foram obtidos também através da entrevista do Secretário de Agricultura e Meio Ambiente do Município.

Palavras-chave: Turismo Rural, Empoderamento, Mulher.

\section{MUJERES EN TURISMO RURAL: UN ESTUDIO EN LA RUTA CIRCUITO DO SOL EN EL MUNICIPIO DE NOVA AURORA-PR}

\section{RESUMEN}

Este artículo tiene como objetivo brindar un análisis de las experiencias de las mujeres en las agroindustrias y su empoderamiento desde la organización de la Ruta Circuito do Sol en el Municipio de Nova Aurora, con el enfoque de Turismo Rural y Empoderamiento Femenino. Los datos fueron recolectados mediante investigación cualitativa, bibliográfica y documental, entrevistas semiestructuradas y visitas a agroindustrias pertenecientes al Circuito do Sol, Ayuntamiento y Emater. Luego de realizar las entrevistas y visitas a las agroindustrias, se puede decir que la presencia del empoderamiento de las mujeres organizadas en turismo rural en el municipio de Nova Aurora es visible. Con base en los relatos de las mujeres entrevistadas, se verifica un sentimiento de miedo al inicio de la actividad, pero de aprecio, orgullo y aumento de la autoestima por el puesto alcanzado a lo largo del tiempo. Los resultados también se obtuvieron a través de una entrevista con la Secretaría Municipal de Agricultura y Medio Ambiente.

Palabras clave: Turismo Rural, Empoderamiento, Mujeres.

\section{THE WOMAN IN RURAL TOURISM: A STUDY IN THE ROUTE CIRCUIT OF THE SUN OF THE MUNICIPALITY OF NOVA AURORA- PR}

\section{ABSTRACT}

This article aims to provide an analysis about women's experiences in agro-industries and their empowerment from the organization of the Road Map Circuit of the Sun in the city of Nova Aurora, with the Rural Tourism approach and Female Empowerment. The data were collected by means of qualitative, bibliographic and documentary research, deciphering the semi-structured and visits in agro-industries belonging to the Circuit of the Sun, at the City Hall and at Emater. After conducting the interviews and visits in agro-industries, it can be said that the presence empowerment of the women organized in rural tourism of the city of Nova Aurora is visible. Based in the reports of the women interviewed there is a feeling of fear at the beginning of the activity, although of appreciation, pride and increased self-esteem by position conquered with time. The results were obtained also through of the interview of the city's Secretary of Agriculture and Environment.

Keywords: Rural Tourism, Empowerment, Women. 


\section{INTRODUÇÃO}

As atividades não agrícolas surgem como estratégias após as mudanças ocorridas no meio rural brasileiro, que trouxeram com elas o desenvolvimento de novas formas de uso do espaço rural, relacionadas ao consumo de novos produtos e serviços, o que tem permitido que o produtor rural, que era somente responsável pela produção de matéria-prima, passe a ser um prestador de serviços, diversificando suas formas produtivas através das agroindústrias familiares e áreas de lazer.

Como forma de disseminar as ideias e criatividades no espaço rural, surgem roteiros de turismo rural em diferentes regiões do país que tem incentivado muitos agricultores a desenvolverem o turismo, modificando o ritmo de vida local e a estrutura na divisão das atividades, tanto no turismo quanto na agricultura e no ambiente doméstico, assim como os valores sociais, culturais, ambientais e econômicos dos agentes envolvidos.

O objetivo deste estudo é analisar o empoderamento das mulheres envolvidas no Roteiro Circuito do Sol do município de Nova Aurora, caracterizando as agroindústrias e áreas de lazer, a fim de entender como foi disseminado e organizado os agentes envolvidos neste roteiro, destacando as dificuldades e evidenciando as mudanças ocorridas na vida das mulheres inseridas neste contexto.

Este artigo encontra-se estruturado da seguinte forma: introdução; desenvolvimento: abordando turismo rural, turismo no espaço rural e sustentabilidade, empoderamento feminino, método e metodologia, o caso Roteiro do Circuito do Sol e os resultados alcançados; e, por último, as considerações finais e referências.

\section{TURISMO RURAL}

Em razão de ser o turismo uma atividade socioeconômica recente, bem como em virtude de seu caráter interdisciplinar, Sancho (1998) aborda a dificuldade de se apresentar uma definição consolidada e clara que seja capaz de delimitar a atividade turística e a distinguir de outros ramos. Após mencionar diversos conceitos adotados ao longo dos últimos anos, destaca aquele utilizado pela Organização Mundial do Turismo (OMT).

Nesse sentido, o autor menciona que o turismo compreende as atividades realizadas pelas pessoas durante viagem e estadias em lugares diversos de seu entorno habitual, por período consecutivo inferior a um ano, com o objetivo de lazer, negócios ou outros.

Fontana e Flores $(2013$, p. 2) preceituam que o turismo pode ser considerado atualmente uma atividade de especial importância econômica e social, sendo um fator fundamental no processo de desenvolvimento das comunidades. Destacam que tal relevância se justifica em especial pelo atendimento às necessidades do ser humano, as quais são exemplificadas pelos autores como "espaço, movimento, bem-estar, expansão e repouso, longe das tarefas impostas pelo cotidiano; induzindo o homem a conhecer novos prazeres e descobrir novos horizontes na tentativa de escapar de sua rotina diária.". 
De acordo com o Ministério do Turismo (2010), o turismo rural teve início como atividade econômica no município de Lages/SC, onde as primeiras propriedades rurais abertas à visitação surgiram no ano de 1986 como alternativa às atividades agrárias comuns.

No mais, o Ministério do Turismo (2003) destaca que a definição de turismo rural se fundamenta em aspectos que se relacionam ao turismo, ao território, à base econômica, aos recursos naturais, culturais e à sociedade, conceituando o turismo rural como "o conjunto de atividades turísticas desenvolvidas no meio rural, comprometido com a produção agropecuária, agregando valor a produtos e serviços, resgatando e promovendo o patrimônio cultural e natural da comunidade".

Para Fontana (2005) o turismo rural é considerado sob a seguinte perspectiva:

As atividades turísticas praticadas em propriedades rurais produtivas, envolvendo a população local, seus usos e costumes, com a finalidade de complementar a renda e valorizar a cultura dos residentes, ao disponibilizar uma opção de turismo alternativo que vá ao encontro às necessidades de lazer do homem urbano (p. 21)

Partindo de tais conceitos, constata-se que a atividade, para que seja considerado como turismo rural, deve acontecer em espaço não urbano e advir de uma série de representações que remetam o turista ao ambiente rural e suas caracterizações.

Dessa maneira, Marinho e Bruhns (2003), ao tratarem de turismo rural, destacam que tal ramo surge como um destino cercado de usos e significados, constituindo a valorização e maior interesse pela qualidade de vida um fator determinante para o aumento da procura pelo turismo rural.

Além disso, para os autores, o turismo rural também oferece contato com o patrimônio artístico e com a sociabilidade de comunidades rurais, interações estas que permitem uma aproximação com dinâmicas diferentes da urbana, e a novas percepções culturais.

Logo, Marinho e Bruhns (2003) concluem que o turismo rural corresponde ao coletivo de incursões turísticas de lazer praticadas no campo, mas interligadas ao modo de produção agropecuário e aos recursos naturais e culturais, entendendo a sustentabilidade da atividade para além de fatores financeiros.

\subsection{O turismo no espaço rural -TER e sua relação com o contexto sustentável}

De acordo com Souza e Elesbão (2011, p. 78), a atividade turística no meio rural predita a uma dinamização da economia local no espaço rural, favorecendo ao surgimento de novas atividades lastreadas por meio das iniciais, agindo de tal modo no "desenvolvimento da capacidade empreendedora por mobilizar recursos que até então se encontravam ociosos nas propriedades", mas tornando-se sem margem de dúvidas, um espaço alvo de múltiplas intervenções e incrementos. 
No que se refere aos principais problemas para o desenvolvimento do turismo rural, Toresan, Mattei e Guzzatti (2002) destacam a insuficiência de recursos próprios, a dificuldade de financiamento, a falta de capacitação e a pouca mão de obra familiar.

Nessa perspectiva, Toresan et al (2002) sugerem a criação de um quadro-guia para a atividade de turismo rural, que seja aplicável nacionalmente, mas que possibilite a existência de normas adaptáveis às condições e interesse de regiões e estado, fazendo necessário a formulação de uma política de apoio para fortalecer o turismo nas áreas rurais, com financiamentos que contemplem a realidade do setor e das diferentes modalidades de turismo, além de um programa adequado de divulgação, de capacitação para os agentes de apoio e os produtores envolvidos e recursos financeiros para infraestrutura para os atores envolvidos no turismo em áreas rurais.

Moretto Neto e Agostine (2005, p. 15) abordam, ainda, a impossibilidade de construir o desenvolvimento de uma economia turística sustentada sem contar com a participação dos atores sociais da região, sejam eles de atividades diretas ou indiretas, mencionando que a "integração produtiva setorial, independentemente do território analisado, pode enfrentar óbices naturais o que requer amplo e sistemático esforço de articulação e cooperação dos atores", fatos estes corroborativos nos processos convergentes.

De acordo com Sachs (2000), a sustentabilidade é definida como um enfoque de desenvolvimento socioeconômico orientado para a satisfação de necessidades básicas; 0 reconhecimento do papel fundamental que a autonomia cultural desempenha nesses processos de mudança; e o oferecimento de um conjunto de critérios para avaliar a pertinência de ações mais específicas.

Acerca do tema, Jacobi (1997) preleciona que a noção de sustentabilidade implica em uma interrelação necessária de justiça social, qualidade de vida, equilíbrio ambiental e a ruptura com o atual padrão de desenvolvimento.

Mikhailova (2004) aborda que o desenvolvimento sustentável passou a ser a questão principal de política ambiental somente a partir da Conferência das Nações Unidas sobre Meio Ambiente e Desenvolvimento (Rio-92). Nessa oportunidade, a Organização das Nações Unidas (ONU), através do relatório Nosso Futuro Comum, publicado pela Comissão Mundial para o Meio Ambiente e o Desenvolvimento em 1987, definiu o desenvolvimento sustentável como sendo aquele que almeja satisfazer as necessidades presentes sem comprometer as necessidades das gerações futuras.

Nesse ínterim, conforme destacam Santos e Cândido (2013), é visível a importância de se alcançar a sustentabilidade, sendo notória a repercussão das atividades turísticas nesse processo.

\subsection{Desenvolvimento ambiental X Turismo Rural}

A história do turismo, no mundo e no Brasil, é carregada de episódios que evidenciam o desgaste de áreas de atrativos, exigindo estratégias urgentes que sejam mais responsáveis em relação à atividade turística e, também, que promovam a qualidade de vida das populações humanas 
locais e a conservação do meio ambiente das áreas receptoras, conforme ressaltam Marinho e Bruhns (2003).

Santos e Cândido (2013) enfatizam ser imprescindível que os agricultores tenham ciência da grande responsabilidade que possuem na mudança de paradigma de desenvolvimento, pois suas práticas afetam diretamente o meio ambiente, razão pela qual suas ações devem estar pautadas nos princípios da sustentabilidade como forma de alcançar o desenvolvimento rural sustentável e garantir um turismo de qualidade.

Os autores mencionam, ainda, que os referidos princípios foram retomados e aprofundados na Declaração de Fortaleza (2008), oportunidade em que se enfatizou como necessidade urgente a prática de políticas referentes à validação de garantias e direitos das populações aos seus territórios, bem como a ampliação da participação qualificada destas em instâncias de formulação e deliberação de Políticas Públicas voltadas para o turismo

Conforme preceituam Souza e Elesbão (2011), no Fórum Global sobre Turismo Sustentável (Fórum Social Mundial de Belém do Pará), realizado no ano de 2009, foi elaborado um novo padrão de turismo, considerado não predatório, excludente e insustentável, com esse modelo pode garantir a conservação do ambiente e da beleza cênica natural, com o envolvimento das comunidades, seu desenvolvimento e à autodeterminação, buscando preservar a diversidade ambiental, biológica e cultural.

Ainda para Souza e Elesbão (2011, p. 198), o Código Mundial de Ética do Turismo estabelece "a necessidade de fazer um turismo acessível a todos, responsável e sustentável, com salvaguarda do ambiente e dos seus recursos, em particular dos ecossistemas e da biodiversidade", dando também enfoque à capacidade de carga, à preservação e valorização do patrimônio artístico, arqueológico e cultural, com destaque para os monumentos, santuários, museus, locais históricos e arqueológicos, bem como para as produções culturais e artesanais tradicionais, sem padronização nem empobrecimento, além da aproximação entre populações de culturas e modos de vida diferentes, e ao desenvolvimento econômico e à satisfação de expectativa dos turistas e, em consequência, do proprietário.

\subsection{Empoderamento Feminino através do Turismo Rural}

Em se tratando da atividade turística no espaço rural e suas possibilidades de desenvolvimento da localidade onde ocorre, é necessária a compreensão de que as atividades turísticas possuem um escopo em que elementos constituintes de diversas dimensões se interrelacionam, permitindo avanços nos campos sociais, culturais, econômicos e ambientais, o que confirma o poder de sustentabilidade provocado pelo processo turístico.

A partir dessa premissa, é possível compreender a atividade turística no espaço rural tal qual um modelo econômico capaz de promover o desenvolvimento rural. Nesse sentido, Monteiro (2018, p. 2) aduz que "a atividade do turismo vem sendo reconhecida nas últimas décadas como uma aliada do desenvolvimento". Já Azevedo e Rodrigues (2015) destacam que a presença do turismo no 
espaço rural fortalece a atividade e auxilia no desenvolvimento nas regiões menos favorecidas socioeconomicamente.

Diante disso, a atividade turística possui fundamental relevância no que se refere às possibilidades proporcionadas ao desenvolvimento nos níveis sociais, culturais, econômicos e políticos.

Ademais, ao se abordar questões sociológicas e de gênero, há a necessidade de se destacar o papel das mulheres no desenvolvimento das atividades de turismo rural, uma vez que para o exercício do cotidiano de trabalho, a mulher deixa de ter uma atividade reprodutiva e a torna produtiva.

A autora Lunardi (2010) ressalta a posição de destaque ocupada pela mulher na atividade turística rural, já que se constitui um importante agente no mundo rural, incentivando iniciativas inovadoras de desenvolvimento rural, afirma ainda que a mulher traz consigo o saber/fazer que dinamiza as economias locais, impulsiona o desenvolvimento de novas atividades, incluindo a agroindústria e o turismo rural.

A partir dessa ótica, é conferido um papel de importante significado à mulher rural ao assumir responsabilidades para a consecução das novas atividades relacionadas ao turismo rural, o que funciona como um fator de empoderamento, eliminando a invisibilidade social.

Ainda acerca do tema, Bühler e Souza (2011) destacam a participação da mulher na sociedade e na economia através do desenvolvimento de atividades de turismo rural. Nesse ínterim, constata-se uma nova função da mulher na sociedade, propiciando mudanças na forma de interação social e, por consequência, novos contornos sociais são assumidos por ela.

Para Staduto, Souza e Nascimento (2015, p. 20), o papel social da mulher e do homem do campo é uma relação assimétrica, eis que "a invisibilidade das mulheres é potencializada pelos padrões culturais e pela grande dispersão espacial, tornando mais acentuada a invisibilidade social e do trabalho, e, especialmente na agricultura familiar em que as atividades de produção e reprodução se embaralham".

Essa assimetria de gênero possui forte ligação com o patriarcalismo social vigente em muitas sociedades, em que o homem pouco considera o potencial da mulher. Nesse sentido, a premissa de empoderamento perpassa pelo entendimento de que a mulher é considerada tal qual um agente consciente em relação ao meio com o qual interage e que é tão capaz quanto o homem de tomar decisões nas mais diversas esferas da sociedade.

Os autores Mageste, Melo e Ckagnazaroff (2008) prelecionam que, nas relações de trabalho, a mulher almeja reconhecimento por sua competência e a possibilidade de competir de igual para igual, não se submetendo apenas ao poder masculino.

A respeito do empoderamento feminino, Lunardi, Souza e Perurena (2015) afirmam que segundo estudo nos países como a Espanha e a França, a participação e o envolvimento da mulher nas atividades de turismo rural são evidenciados como força motriz importante no seu desenvolvimento, assumindo uma posição central em unidades turísticas.

Nesse sentido, Malhotra, Schuler e Boender (2002) apresentam cinco dimensões do empoderamento das mulheres: econômica (o controle dos rendimentos e recursos da família são 
controlados pela mulher); sociocultural (liberdade de vir e ir, acesso aos espaços sociais, participação de grupos e redes sociais); familiar e interpessoal (tomadas de decisões domésticas, decisões de relacionamentos); legal e política (conhecimento dos direitos); e psicológica (Autoestima, auto eficiência, bem-estar, denúncia de injustiças, potencial de mobilização).

Percebe-se, portanto, que há um destaque para o gênero feminino no que se refere ao turismo no espaço rural e sua forma de condução, pois a mulher, ao assumir um outro papel social, desvincula-se da tradicionalidade de sua função e, a partir disso, melhora sua autoimagem, confiança e acaba desenvolvendo novas capacidades e domínios para assumir novos papéis de destaque frente a sociedade.

O empoderamento feminino, seja no turismo rural, seja em outras circunstâncias da vida da mulher junto ao meio com o qual se relaciona, verifica-se sob a égide de uma alteração do papel desenvolvido pelas mulheres na sociedade atual e rompimento com velhos paradigmas, modificando suas experiências e também a forma como é vista e entendida pela sociedade.

\section{MATERIAIS E MÉTODOS}

O Estudo foi desenvolvido no Roteiro Circuito do Sol no município de Nova Aurora - Paraná, através de pesquisa qualitativa que, segundo Richardson (1999), busca a compreensão dos significados e características situacionais coletados através de entrevistas ao invés de produção de medidas quantitativas.

A classificação da pesquisa se dá sob dois aspectos: quanto aos fins, é descritiva, conforme conceito apresentado por Vergara (1997), e em relação aos meios, pode ser considerada um estudo de caso, uma vez que analisa agroindústrias que fazem parte do Roteiro Circuito do Sol. Nessa perspectiva, Gil (2010) assegura que as pesquisas descritivas têm como objetivo a descrição das características de determinada população estabelecidas nas relações entre variáveis. Já para Yin (2001, p. 32), o estudo de caso "é uma investigação empírica que investiga um fenômeno contemporâneo dentro de seu contexto da vida real".

Para a efetivação deste estudo, foram ouvidos em entrevista semiestruturada, o Secretário de Agricultura do Município de Nova Aurora, precursor das atividades do turismo rural do município desde 0 ano de 2005 até o momento, dez mulheres que fazem parte das agroindústrias e das atividades do turismo rural. A escolha da amostra foi intencional, pois, com base no que preceitua Richardson (1999), os elementos que fazem parte desta amostra foram definidos pelo objetivo e certas características da pesquisa. Diante disso as mulheres que estão à frente das agroindústrias que fazem parte do Circuito do Sol, foram convidadas e das doze, dez aceitaram fazer parte deste estudo. As entrevistas foram gravadas e previamente agendadas com os envolvidos.

\section{RESULTADOS ALCANÇADOS}

A colonização de Nova Aurora deu-se a partir da década de 1940, segundo Nossa História (2019) quando algumas famílias se estabeleceram em um lugar conhecido então por Encruzilhada 
Tapejara. A evolução colonizadora da região iniciou-se por conta da campanha getulista - Marcha para o Oeste. As terras férteis incentivaram os primeiros moradores, que deram início à formação do povoamento que se transformou em distrito, subordinado a Cascavel, em 1961, sendo emancipado em 25 de setembro de 1967. Devido ao seu potencial, o município recebeu o título de Capital Paranaense da Tilápia em setembro de 2017.

Com os dados coletados na prefeitura do município, a agricultura, agropecuária e o setor de prestação de serviços correspondem às principais fontes de renda do município. Mesmo com bons resultados na cultura convencional de soja, milho e trigo, os pequenos produtores, visando manter-se no meio rural, estão em busca de outras formas de produção.

Inicialmente, realizou-se entrevista com o Secretário da Agricultura e Meio Ambiente do município de Nova Aurora, João Jamil Moreni Bernis, precursor do Turismo Rural em 2005, data em que ainda era funcionário da Emater, disponibilizou documentos, fotos e materiais para a colaboração da pesquisa. Dentre os dados apresentados, mencionou as principais características das agroindústrias que integram o Roteiro Circuito do Sol do município, a partir das quais se iniciou a estruturação do estudo.

Com a presença de parcerias com o Estado e o Município, Emater, Sindicato Rural e Prefeitura, através de cursos oferecidos pelo SENAR e SEBRAE, a partir do ano de 2005, a criatividade aliada à visão de empreendedorismo tem feito com que muitos produtores investissem em atividades não agricultáveis, tais como as agroindústrias, áreas de lazer e o turismo rural.

Declarou que foi fundamental aos envolvidos os cursos e treinamentos do SENAR e SEBRAE, e as visitas em outras cidades, propriedades e feiras que participaram em 2005, 2006 e 2007. Com base nesse conhecimento e experiências, em 2008 constituíram o Roteiro Circuito do Sol, a partir do ano de 2009, começaram as visitas no município de Nova Aurora, época em que já havia organização e estrutura para receber os turistas, os quais vinham para conhecer e ouvir os cases do município.

O entrevistado Jamil afirma que em alguns anos receberam mais de 60 (sessenta) excursões com cerca de 40 (quarenta) pessoas, mencionando que em um único dia mais de 3 (três) comitivas compareceram na localidade. Aduz, ainda, que as pessoas vinham da região, de outros estados brasileiros e de outros países, como Paraguai e França.

Também afirma, na entrevista, que em 2009, 10 (dez) propriedades recebiam visitantes, dentre elas 7 (sete) agroindústrias e 3 (três) áreas de lazer, enquanto, atualmente, 11 (onze) das 16 (dezesseis) propriedades aceitam visitações. Nessas propriedades residem famílias compostas por casais e, em alguns casos, filhos e, além da agroindústria e turismo rural, na maioria delas, desempenham-se atividade de agricultura e produção de peixe, frango e leite.

Assim como Lunardi (2010) destacam a mulher como importante agente e principal incentivadora em iniciativas inovadoras de desenvolvimento rural, trazendo consigo o saber fazer, Jamil complementa em sua entrevista que a maioria dos elogios recebidos nas visitas do turismo rural eram para as mulheres. "aqui em Nova Aurora na questão das agroindústrias e turismo as mulheres saíram na frente", além de ser um espaço da propriedade que na maioria das vezes é cuidado pela mulher, elas de um modo geral organizam e cuidam melhor do paisagismo, "faz parte 
da essência da mulher". Afirma também que nas agroindústrias de Nova Aurora $80 \%$ as mulheres estão à frente.

Para finalizar a entrevista de Jamil, destaca que as pessoas precisam acreditar mais em seus sonhos, para o futuro precisam o envolvimento de todos e principalmente para o turismo ser promissor em um município necessita de um tripé, político, técnico e operacional, com isso, alcançarão o sucesso esperado.

Ao todo, 14 (quatorze) agroindústrias e 2 (duas) áreas de lazer constituem o roteiro, seja com visitações seja com produtos disponibilizados para as visitas, entretanto apenas 10 (dez) delas foram objeto de estudo da presente pesquisa, tendo sido realizada entrevista dos envolvidos. Com o objetivo de melhor compreender a organização de cada agroindústria, segue quadro explicativo acerca das principais características:

\section{Tabela 1:}

Caracterização das Agroindústrias do Circuito do Sol

\begin{tabular}{llll}
\hline AGROINDÚSTRIAS & ATORES & $\begin{array}{l}\text { INÍCIO } \\
\text { ATIVIDADES }\end{array}$ & $\begin{array}{c}\text { DAS } \\
\text { PRINCIPAL } \\
\text { PRODUTO }\end{array}$ \\
\hline CONGELADOS PETRY & ÂNGELA/CARLOS & 2006 & Massas \\
DOCE SABOR & NADIR/FREDI & 2006 & Suspiros \\
ENGENHO AGOSTINI & VILSON/CRIS & 2006 & Rapadura \\
VITALLYS CONGELADOS & TÂNIA/MARIVALDA & 2006 & Salgados \\
CHAPÉU DE PALHA & MARLENE & 2006 & Pães \\
PESQUE PAGUE SANDRI & MERI/ALTAIR & 2006 & Restaurante \\
FRIGORÍFICO DE PEIXES & SALETE/DILAINE & 2006 & Filé /Tilápia \\
ABATEDOURO SÃO JOSÉ & MARLEI/CARLOS & 2006 & Frango \\
SALGADOS LOTTI & TEREZINHA & 2014 & Salgados \\
BOLACHAS ADULCE & SIRLENE & 2018 & Bolachas \\
\hline
\end{tabular}

Fonte: dados da pesquisa

Dados coletados junto às entrevistas realizadas demonstram que todas as agroindústrias destacadas no quadro 1 fazem parte do Roteiro Circuito do Sol, sendo que 8 (oito) delas iniciaram junto com as atividades do Roteiro. Todas elas obtiveram incentivos da Emater e da Prefeitura Municipal de Nova Aurora, tendo o auxílio do entrevistado Jamil.

No mais, todas as agroindústrias necessitaram de financiamentos, com projetos desenvolvidos pela Emater e crédito do PRONAF, com prazos de 10 (dez) para pagamento com $2 \%$ (dois por cento) de juros ao ano, tendo a maioria das entrevistadas destacado que o financiamento foi utilizado apenas para a estrutura física. No que se refere à estrutura física, a agroindústria Vitallys utiliza uma construção cedida pela Prefeitura para Agroindústrias, enquanto todas as demais possuem estruturas construídas em suas propriedades. Souza e Elesbão (2011) afirmam que adquirir um financiamento é uma das dificuldades encaradas pelos empresários turísticos, porém nestes casos analisados não foram identificados nenhuma dificuldade para adquirir os financiamentos e todos conseguiram esse recurso. 
Entre os principais produtos fabricados pelas agroindústrias objeto da presente pesquisa, destacam-se massas, salgados, suspiros, rapadura e melado, pães, filé de tilápia, frango e bolachas.

\subsection{Resultados das Entrevistas com as Mulheres}

A seguir, serão apresentados dados obtidos nas entrevistas realizadas com 10 (dez) mulheres que integram agroindústrias e áreas de lazer pertencentes ao Roteiro Circuito do Sol, formulando-se questionamentos relacionados ao início das atividades da agroindústria familiar e aos principais momentos no turismo rural, objetivando verificar a importância da mulher como forma de responder ao objetivo da pesquisa.

Algumas informações obtidas com o estudo são apresentados no quadro a seguir:

\section{Tabela 2}

Caracterização das Mulheres Entrevistadas

\begin{tabular}{llll}
\hline AGROINDÚSTRIAS & IDADE & QUEM AJUDA & O QUE FAZIA ANTES \\
\hline ENTREVISTADA 1 & 56 & Esposo na Produção & Vendedora/Empresária \\
ENTREVISTADA 2 & 54 & Esposo na Entrega & Doméstica/funcionária mercado \\
ENTREVISTADA 3 & 56 & Esposo na Produção & Empregada Doméstica/cartório \\
ENTREVISTADA 4 & 39 & Sozinha & Vendedora/Empresário \\
ENTREVISTADA 5 & 47 & Funcionários & Auxiliar Financeira \\
ENTREVISTADA 6 & 56 & Funcionários & Dona de casa/vendedora informal \\
ENTREVISTADA 7 & 52 & 2 Casais/Funcionários & Dona de casa/agricultura \\
ENTREVISTADA 8 & 53 & Filha & Suínos/agricultura \\
ENTREVISTADA 9 & 46 & Sozinha & Dona de Casa \\
ENTREVISTADA 10 & 57 & Esposo na Produção & Plantava mandioca/fumo \\
\hline
\end{tabular}

Fonte: dados da pesquisa

Com a finalidade de complementar o quadro 2, as entrevistadas 3, 7 e 8 destacaram que apenas contratam outras pessoas no período em que há o aumento de demanda, enquanto as entrevistadas 5 e 6 mencionaram que já possuem funcionários contratados, empregando temporariamente outras pessoas quando necessitam de mais produção.

A entrevistada 7 afirmou que, nas situações de aumento de clientes, conta também com o auxílio da filha no período da noite e nos finais de semana. Do mesmo modo, a entrevistada 8 afirma que a filha é seu "braço direito", já que a auxilia em todas as decisões e planejamento das atividades diárias.

Ao tratarem do aumento de demanda e necessidade de contratações temporárias, as entrevistadas 2, 3, 5 e 8 mencionaram possuir grande dificuldade nesse aspecto, relatando que tiveram problemas relacionados à qualidade e padronização dos produtos, assim como ao atendimento dos clientes nas situações em que empregaram outras pessoas. Nesse sentido, destacaram que adotaram novas estratégias de planejamento e, não sendo suficiente para suprir a demanda, optaram por reduzir o número de pessoas atendidas com a finalidade de preservar a qualidade dos produtos. 
No quadro 2, são apresentadas também as principais atividades que as mulheres exerciam antes de serem empresárias do turismo. Nessa perspectiva, as entrevistadas 3 e 9 afirmam que, após casarem, ficaram por muito tempo sendo empregadas dos maridos, sem nenhuma remuneração, destacando que o principal incentivo foi o desejo de obter seu próprio dinheiro. Por sua vez, a entrevistada 4 ressaltou que nunca dependeu financeiramente de seu marido, pois exercia atividades como empresária e como vendedora e, ao ter que deixar seu emprego para ficar com a filha no período em que ela não estava na creche, viu na abertura da agroindústria uma forma de manter sua independência financeira.

Além das informações contidas no quadro em análise, quanto à escolaridade, 3 (três) das mulheres entrevistadas responderam não possuir o ensino fundamental finalizado, 4 (quatro) destacaram ter concluído o ensino fundamental e 3 (três) informaram possuir ensino médio completo.

Quando questionadas acerca do incentivo ao início das atividades de turismo rural, 7 (sete) das entrevistadas afirmaram que participaram de um curso com duração de dois dias sobre turismo rural com o Professor Jacó Gimenes, que foi organizado pela Emater com o auxílio de parceiros, tais como o Município e o Sindicato Rural. Além disso, destacaram outros cursos e especializações capazes de proporcionar o conhecimento necessário para o desenvolvimento de suas atividades.

Outro questionamento apresentado na entrevista foi relacionado aos desafios no início das atividades do turismo rural, constatando-se que todas as mulheres apresentaram dificuldades. Nesse sentido, a entrevistada 1 afirmou que a decisão de ser presidente do Conselho do Turismo foi difícil e trouxe a necessidade de conhecimento e determinação, sendo que cinco das entrevistadas apontaram como desafio a necessidade de melhorar e ampliar os sabores das receitas já utilizadas em sua produção.

Ainda acerca de tal aspecto, a entrevistada 3 afirmou que não gostava de cozinhar e que, quando solteira, ocupava-se de outras atividades domésticas e que, atualmente, produz diversos alimentos de receitas italianas. Outro ponto abordado pela entrevistada foi relacionado à timidez como um desafio no turismo, pois acreditava ser esse um empecilho para o atendimento de pessoas em sua propriedade. Por sua vez, as entrevistadas 4 e 9 apresentaram que a maior dificuldade foi a não aceitação dos esposos no investimento e, com isso, a preocupação no pagamento do financiamento a partir da construção das estruturas, bem como a falta de conhecimento em gestão e na formação de preço dos produtos.

Para as entrevistadas 5 e 6 , adquirir a matéria-prima era a maior dificuldade, pois para produzirem tinham que ir até o fornecedor, que se situava na zona urbana do município ou em outras cidades e, em razão de a empresa não possuir carro, era necessário emprestar o carro do marido para realizarem as compras.

Segundo relatos das entrevistadas, as dificuldades e medos foram superados com força de vontade e também com o auxílio dos cursos e treinamentos oferecidos pelo SENAR e SEBRAE, assim como de atividades com o professor Jacó e de ajuda diária do Jamil, atualmente Secretário da Agricultura do município e na época funcionário da Emater, o qual foi mencionado como "um anjo na vida delas" por uma das entrevistadas, além das trocas de experiências e conversas informais no 
grupo do turismo de Nova Aurora e nas visitas técnicas em outras cidades, as quais fortaleceram as informações e conhecimentos sobre a organização do turismo.

As entrevistadas também foram perguntadas quanto à conciliação das atividades na vida diária: 8 (oito) das mulheres afirmam que, caso necessário, deixam de realizar as atividades domésticas para que consigam desempenhar as atividades do turismo e da agroindústria, as quais veem como prioridade. No mais, as entrevistadas 4 e 8 afirmam que o planejamento é o ponto principal para o cumprimento de todas as atividades na propriedade, tanto de organização da casa, como também nas atividades de paisagismo, na conclusão dos pedidos das demandas e no atendimento dos visitantes no turismo rural. Ainda acerca de tal ponto, a entrevistada 10 afirma que: "[...] se precisar deixar alguma coisa, deixo roupa para lavar, casa para limpar, mas deixar de fazer a caminhada eu não deixo, faço o almoço a noite, arrumo a marmita e o café, tiro tempo para ir na lanchonete, na igreja, ir na casa do filho e fazer a caminhada".

Ponto importante questionado na pesquisa foi relacionado à renda, tendo apenas duas das entrevistadas informado um valor certo: A entrevistada 7 afirmou ter uma renda líquida de $R \$$ $3.000,00$ (três mil reais), enquanto a entrevistada 9 mencionou obter renda mensal correspondente a $\mathrm{R} \$ 2.000,00$ (dois mil reais), destacando, porém, que não há um controle correto disso e que, em alguns meses, essa renda aumenta significativamente, já que tudo que produzem na propriedade é entregue à Coperafa e não há desperdício, como, por exemplo, "o abacate, temperos, mandioca, entre outros produtos".

Ademais, 3 (três) das entrevistadas relataram que 50\% (cinquenta por cento) da renda da família vem da agroindústria e do turismo rural, 2 (duas) entrevistadas ressaltaram ser $30 \%$ (trinta por cento), 1 (uma) delas informou que os lucros obtidos com a empresa é a única renda familiar e a entrevistada 4 afirmou que o lucro obtido representa $5 \%$ (cinco por cento) da renda familiar, relatando ser suficiente para suprir suas necessidades individuais e não depender do esposo. Acerca dos rendimentos verificados, a entrevistada 10 declarou: "minha carteira nunca mais ficou sem dinheiro".

Outro questionamento foi quanto à presença machista em atitudes do desenvolvimento da agroindústria e do turismo rural. Ao responder a referida pergunta, a entrevistada 1 destacou: "no começo o meu marido ficou meio assim, [...] acham que eles são donos da gente né mas daí como você encara, você enfrente e você faz, de boa, entra junto, encara". No mais, duas das entrevistadas afirmaram que, antes da criação das agroindústrias, eram domésticas dos maridos e não possuíam nenhum reconhecimento.

Além disso, a entrevistada 9 afirmou: "senti na pele, meu marido, quando eu comecei, disse que eu não iria conseguir e não iria dar conta e esse foi meu incentivo e eu consegui", destacando, ainda, que para participar de visitas e feiras, os colegas do turismo tinham que conversar com o marido para que ele aceitasse a sua participação. Ressaltou, ainda, que atualmente sente que há a aceitação, no entanto a angústia e o medo ficam claros no depoimento de algumas entrevistadas.

A entrevistada 4 relatou que se sentiu desafiada nos momentos em que o marido the perguntou sobre o valor do investimento e se teria condições de pagar as prestações de sua agroindústria. As entrevistadas 5 e 6 destacaram terem recebido muitas críticas de familiares que 
mencionavam sentirem vergonha de visualizarem a venda porta a porta para a apresentação dos produtos industrializados.

Ainda acerca de tal aspecto, a entrevistada 8 asseverou que amigos do marido diziam que ele a "escravizava" ao saberem que ela realizava o corte de lenha com motosserra, a poda das gramas e o paisagismo da propriedade. Ela, entretanto, destacou que não aceitou esse posicionamento e continuou a desempenhar tais atividades, por se sentir bem e valorizada.

Abordando a satisfação no envolvimento do turismo rural, todas as entrevistadas afirmaram estarem satisfeitas, destacando, dentre outros motivos, a valorização das pessoas quanto à organização e estruturação nas visitas, receitas e paisagismos dos ambientes. Além disso, muitas entrevistadas afirmaram que a satisfação advém também do cuidado pessoal com a aparência (unha, sobrancelha, cabelo, cuidados físicos, roupas, entre outros).

Nesse contexto, a entrevistada 1 ressaltou que, além de ser líder no turismo e no conselho de turismo, sempre participou de feiras, tanto nas cidades maiores do Paraná, tais como Maringá, Foz do Iguaçu, Londrina, Ponta Grossa, assim como na capital em Curitiba, além de cidades em outros Estados, como, por exemplo, Porto Alegre, São Paulo, Brasília e Rio de Janeiro, oportunidades em que seu case é apresentado. Mencionou, ainda, que participa há anos do show rural, demonstrando seus produtos, o que a torna conhecida no país todo.

A entrevistada 2 salientou que a qualidade e a padronização dos seus produtos, bem como o cumprimento de pedidos nos prazos estabelecidos faz com que constantemente receba elogios e garante a fidelização dos clientes. Ao responder o questionamento, a entrevistada 3 mencionou que além de todas as conquistas que teve, melhorou também o relacionamento com as pessoas, trabalhando sua timidez e comunicação, assim como a qualidade dos produtos. Com a experiência obtida, passou a não ter medo de assumir pedidos maiores que antes aceitava, mencionando que consegue com facilidade receitas e informações necessárias na internet e com base no relato de outras pessoas.

Outro depoimento que merece destaque é o da entrevistada 5 , a qual relatou que sua agroindústria se localiza em um distrito do município e receber pessoas para conhecer suas atividades fez muita diferença em sua localidade, Nesse sentido, mencionou: "todos duvidavam que algum dia teria turista em Palmitópolis" e continuou afirmando: "teve dias de ter duas e até três comitivas em nossa comunidade".

Nessa perspectiva, a entrevistada 6 afirmou: "eu, no início, tinha que buscar matéria prima em outros municípios e, com o passar do tempo e o aumento da produtividade, os fornecedores entregavam em grande quantidade os produtos utilizados para a fabricação". A entrevistada 7 destacou que, antes da instituição da agroindústria, era dona de casa e não sabia dirigir, sendo que hoje desenvolve atividades como organização, controle, bancos, compras, relatando que não deseja voltar "para o cabo de inchada", auxiliando o marido na roça.

Dando sequência, as entrevistadas 8 e 9 afirmaram que a maior satisfação no dia a dia de suas atividades, advém dos elogios relacionados aos produtos fabricados e da valorização de suas propriedades. Nesse contexto, a entrevistada 9 ressaltou que: "além de mostrar o seu trabalho, a gente compartilha com outras pessoas, nas visitas outras pessoas te conhecem, há depoimentos, eu 
incentivo as pessoas e eles me incentivam". Destaca, também, o seu crescimento pessoal, mencionando que comprou um carro novo, aprendeu a dirigir e voltou a estudar, tendo concluído o ensino médio. No mais, a entrevistada 10 encerrou afirmando que é muito satisfatório possuir saúde e estar bem com o esposo.

Observando o planejamento a médio e longo prazo com suas perspectivas de futuro, todas salientaram que desejam buscar ainda mais conhecimento, espaço e melhorias, o que se verifica especialmente a partir dos seguintes relatos: "vou longe, quero aumentar só, melhorar", "pretendo melhorar, mas já não estou tão nova, mas em qualidade sim". No mais, relataram que desejam buscar melhorias nas receitas, atendimento e paisagismo, destacando que querem continuar independentes em relação aos maridos. A entrevistada 9 destacou: "quero ser uma boleira profissional, fazer bolo de revista, ser profissional em tudo que fizer e, em um ano, vou conquistar tudo isso".

Com todos os depoimentos acima descritos constata-se a presença do empoderamento da mulheres, quando analisado junto às considerações de Malhotra, Schuler e Boender (2002), que apresentam as cinco dimensões do empoderamento.

\section{CONSIDERAÇÕES FINAIS}

As atividades não agrícolas passam a ser desenvolvidas após o contexto da modernização e inovação nas propriedades, em especial diante das dificuldades verificadas nas atividades agrárias comuns. Nessa perspectiva, o turismo no espaço rural surge como uma das atividades que tomam espaços em diferentes áreas brasileiras, passando os proprietários a se utilizaram da criatividade para a manutenção do campo.

Nesse contexto, constatou-se que as atividades turísticas também são desenvolvidas no município de Nova Aurora/PR, sendo desenvolvidas em 14 (quatorze) agroindústrias e 2 (dois) espaços de lazer, os quais compõem o Roteiro Circuito do Sol. Sob esse aspecto, o presente estudo analisou a importância da mulher no cenário do turismo rural no município acima mencionado, tendo se limitado a 10 (dez) propriedades rurais e entrevista de 11 (onze) pessoas envolvidas.

Após a coleta de dados, verificou-se que, nas propriedades investigadas, como estabelecido no objetivo do estudo, as mulheres possuem especial envolvimento com as atividades do turismo rural e que, a partir de tal aspecto, conquistaram um espaço social e de trabalho que, anteriormente, era ocupado predominantemente pelos homens, demonstrando seu empoderamento com seus depoimentos e resultados.

Assim sendo, a pesquisa realizada no Roteiro Circuito do Sol comprova que a significante atuação das mulheres é essencial ao fortalecimento do turismo rural da cidade de Nova Aurora/PR. A referida conclusão evidencia o empoderamento feminino através das atividades que desenvolvem, vez que favorecem o crescimento pessoal e profissional das mulheres campesinas envolvidas. 


\section{REFERÊNCIAS}

Azevedo, R. M. M.; Rodrigues, C.G.O. (2015). Políticas públicas e turismo rural: um estudo acerca das possibilidades e limitações no município de Apodi (RN). Caderno Virtual de Turismo. Rio de Janeiro, 15(2), 131-145.

Bühler, N.; Souza, M. (2011). O empoderamento das mulheres envolvidas nas atividades de turismo rural no roteiro "Caminhos de Pedra". Bento Gonçalves: II Encontro Semintur JR.

Fontana, R. F. (2005). Desenvolvimento do turismo rural no norte do Paraná: estudo de caso da fazenda Ubatuba/Apucarana/PR. São Paulo. Dissertação. [Dissertação (Mestrado em Hospitalidade) - Programa de Pós-Graduação, Universidade AnhembiMorumbi]. Disponível em: http://www.dominiopublico.gov.br/download/texto/cp001483.pdf. Acesso em 18 jun.2019.

Fontana, R. F.; Flores, L. C. S. (2013). Hospitalidade Virtual x Meios de Hospedagem: análise dos sites dos hotéis fazenda do Paraná. X Seminário da Associação Nacional Pesquisa e PósGraduação em Turismo 15 a 18 de outubro de 2013, Universidade de Caxias do Sul. Disponível em: https://www.anptur.org.br/anais/anais/files/10/[75]x_anptur_2013.pdf. Acesso em 20 jun. 2019.

Jacobi, P. R. (1997). Meio ambiente urbano e sustentabilidade: alguns elementos para a reflexão. In: Cavalcanti, C. (org.). Meio ambiente, desenvolvimento sustentável e políticas públicas. São Paulo. pp. 384-390.

Gil, A. C.(2010). Como Elaborar Projetos de Pesquisa. 5 ed. São Paulo: Atlas.

Lunardi, R. (2010). Mulher, Turismo e Desenvolvimento Rural: O trabalho Feminino na Atividade Turística. In: Santos, E. O; Souza, M. (Org.). Teoria e Prática do Turismo no Espaço Rural. Barueri, SP: Manoel.

Lunardi, R.; Souza, M.; Perurena F.(2015). O trabalho de homens e mulheres no Turismo Rural em São José dos Ausentes: o "leve" e o "pesado". Revista Turismo, Visão e Ação Eletrônica,17(1).

Mageste, G. S.; Melo, M. C. O. L.; Ckagnazaroff. I. B. (2008). Empoderamento de mulheres: uma proposta de análise para as organizações. Encontro De Estudos Organizacionais, V, Anpad, Belo Horizonte. Disponível em: http://www.anpad.org.br/admin/pdf/EnEO548.pdf. Acesso em 15 jun. 2019.

Malhotra, A.; Schuler, S. R.; Boender, C. (2002). Measuring Women's Empowerment as a Variable in International Development. World Bank Workshop on Poverty and Gender: New Perspectives. Disponível em: https://www.semanticscholar.org/paper/Measuring-Women\%E2\%80\%99-s-Empowerment-as-a-Variable-in-

Malhotra/326b504f1c6dbf711891118ef7d0eeac9494342c. Acesso em: 15 jun 2019.

Marinho, A.; Bruhns, H. T. (2003). Turismo, Lazer e Natureza. Barueri, SP: Manole.

Mikhailova, I. (2004). Sustentabilidade: Evolução dos Conceitos Teóricos e os Problemas da Mensuração Prática. Revista Economia e Desenvolvimento, $\mathrm{n}^{\circ} 16$. 
Ministério do Turismo. (2003). Diretrizes para o Desenvolvimento do Turismo Rural no Brasil. Brasília: Ministério do Turismo. Disponível em: http://www.turismo.gov.br/sites/default/turismo/o_ministerio/publicacoes/downloads_publicaco es/Diretrizes_Desenvolvimento_Turismo_Rural.pdf. Acesso 16 jun.2019.

Ministério do Turismo. (2010). Turismo rural: orientações básicas. 2.ed. Brasília: Secretaria Nacional de Políticas de Turismo, Departamento de Estruturação, Articulação e Ordenamento Turístico, Coordenação Geral de Segmentação. Disponível em: http://www.turismo.gov.br/sites/default/turismo/o_ministerio/publicacoes/downloads_publicaco es/Turismo_Rural_Versxo_Final_IMPRESSxO_.pdf. Acesso 16 jun. 2019.

Monteiro, F. A. (2018). O Turismo como ferramenta para promover o desenvolvimento social e a preservação do meio ambiente em Piraquara (Paraná, Brasil). Revista Turismo \& Sociedade, Curitiba, 11(3), 518-533.

Moretto Neto, L. M.; Agostine. J. C. (2005). Caminhos do turismo integrado ao Lago de Itaipu: um exercício de cidadania para um desenvolvimento sustentado. Florianópolis: [s.e].

Nossa História. (2019). História do Município de Nova Aurora. Disponível em: http://novaaurora.pr.gov.br/index.php?sessao=b054603368ncb0\&id=1334. Acesso 14 jun. 2019.

Richardson, J. R. (1999). Pesquisa social: métodos e técnicas. 3 ed. São Paulo: Atlas.

Sachs, W. (2000). Sustainable Development. In: REDCLIFT, M.; WOODGATE, G. The International Handbook of environmental sociology. Cheltenham: Edward Elgar, 71-82.

Sancho, A. (Dir) (1998). Introducción al turismo. Organización Mundial del Turismo, 1 ed. Madrid. Disponível em: https://www.academia.edu/15784912/Introduccion_al_turismo_sancho_OMT. Acesso em: 20 jun. 2019.

Santos, J. G.; Cândido, G. A. (2013). Sustentabilidade e agricultura familiar: um estudo de caso em uma associação de agricultores rurais. Revista de Gestão Social e Ambiental - RGSA, São Paulo, 7(1) 70-86.

Souza, M.; Elesbão, I. (2011). Turismo rural: iniciativas e inovações. Porto Alegre: Ed. UFRGS.

Staduto, J. A. R; Souza, M.; Nascimento, C. A. (2015). Desenvolvimento Rural e Gênero: abordagens analíticas, estratégias e políticas públicas. Porto Alegre: Ed. Da UFRGS.

Toresan, L.; Mattei L.; Guzzatti, T. C. (2002). Estudo do potencial do agroturismo em Santa Catarina: impactos e potencialidades para a agricultura familiar. Florianópolis: Instituto Cepa. Disponível em: http://docweb.epagri.sc.gov.br/website_cepa/publicacoes/estudo_potencial.pdf. Acesso em 19 jun. 2019.

Toresan, L.; Guzzatti, T. C.; Nart, D.; Bitencourt, R. B. (2002) Levantamento dos Empreendimentos de Turismo no Espaço Rural de Santa Catarina: Localização, Categorização e Descrição Geral. Florianópolis: Instituto Cepa. Disponível em: http://docweb.epagri.sc.gov.br/website_cepa/publicacoes/levantamento_agroturismo.pdf. Acesso em 19 jun.2019.

Vergara, S. C. (1997). Projetos e relatórios de pesquisa em administração. São Paulo: Atlas. 
Yin, R. K. (2001). Estudo de caso: planejamento e métodos. Traducão de Daniel Grassi. 2. ed. Porto Alegre: Bookman.

$$
\text { Apêndice - Instrumento de Coleta de Dados }
$$

Roteiro de entrevista para as mulheres

1. Quando iniciou o turismo rural em Nova Aurora?

2. Tem um nome dado para o turismo rural aqui em Nova Aurora?

3. Como iniciou o turismo rural em Nova Aurora?

4. Quantas agroindústrias faziam parte na época?

5. Quantas estão presentes nesse turismo hoje? Ao total são quantos membros? E todos de origem do campo?

6. Tiveram treinamento e desenvolvimento através de parcerias? Com quem? Repasse de algum recurso financeiro?

7. Quantas pessoas moram nesta propriedade? Qual o modelo de divisão de tarefas?

8. Qual idade?

9. Estado civil?

10. Desenvolvem outras atividades?

11. O que faziam antes?

12. Alguém da família participava de atividades do turismo rural?

13. O turismo rural auxilia na inserção no mercado de trabalho?

14. Como conciliar as atividades profissionais $x$ familiares?

15. Dificuldades enfrentadas nesse ramo.

16. Questões ambientais que dificultam a permanência neste ramo.

17. Questões climáticas?

18. A qualidade de vida melhorou a partir do envolvimento no turismo rural? Existem outras fontes de receita?

19. Participou de capacitação profissional ou participa?

20. Qual a perspectiva futura no turismo rural?

21. Sentiu em algum momento a presença machista em sua família e no envolvimento do turismo rural?

22. A família auxilia ou atua em conjunto nesta atividade?

23. Você já se sentiu uma empresária do turismo? Qual a maior dificuldade encontrada até hoje?

24. Se sentem realizadas fazendo o que fazem? 